\title{
Healthcare Team Perceptions of a Port- al for Parents of Hospitalized Children Before and After Implementation
}

\author{
Michelle M. Kelly1,2; Shannon M. Dean'; Pascale Carayon2,3; Tosha B. Wetterneck 2,3,4; Peter L. T. Hoonakker ${ }^{2}$ \\ ${ }^{1}$ Department of Pediatrics, University of Wisconsin School of Medicine and Public Health; \\ ${ }^{2}$ Center for Quality and Productivity Improvement, University of Wisconsin-Madison; \\ ${ }^{3}$ Department of Industrial and Systems Engineering, University of Wisconsin-Madison; \\ ${ }^{4}$ Department of Medicine, University of Wisconsin School of Medicine and Public Health;
}

\section{Keywords}

Inpatient, pediatrics, engagement, health information technology, and personal health record

\section{Summary}

Background. Patient electronic health record (EHR) portals can enhance patient and family engagement by providing information and a way to communicate with their healthcare team (HCT). However, portal implementation has been limited to ambulatory settings and met with resistance from HCTs.

Objective. We evaluated HCT perceptions before and 6-months after implementation of an inpatient EHR portal application on a tablet computer given to parents of hospitalized children. Methods. This repeated cross-sectional study was conducted with HCT members (nurses, physicians, ancillary staff) on a medical/surgical unit at a quaternary children's hospital. From December 2014-June 2015, parents of children $<12$ years old were given a portal application on a tablet computer. It provided real-time vitals, medications, lab results, schedules, education, HCT information and a way to send the HCT messages/requests. HCT members completed surveys pre- and post-implementation regarding their portal perceptions. Pre-post differences in HCT perceptions were compared using chi-squared, Mann-Whitney and Kruskall Wallis tests.

Results. Pre-implementation, $\mathrm{HCT}$ respondents $(\mathrm{N}=94)$ were generally optimistic about the benefits of a portal for parents; however, all anticipated challenges to portal use. Over the next 6-months, 296 parents used the portal, sending 176 requests and 36 messages. Post-implementation, HCT respondent $(\mathrm{N}=70)$ perceptions of these challenges were significantly reduced (all $p<0.001)$, including: parents (will) have too many questions ( $69 \mathrm{vs.} \mathrm{3 \% ,} \mathrm{pre-post),} \mathrm{parents} \mathrm{(will)} \mathrm{know} \mathrm{results} \mathrm{before}$ the HCT ( 65 vs. $1 \%$ ), staff (would be/are) skeptical ( 43 vs. $21 \%$ ) and there (will be/is) not enough technical support (28 vs. $1 \%$ ).

Conclusions. All HCT respondents anticipated challenges in providing a portal to parents of hospitalized children; however, these concerns were minimized after implementation. 


\section{Correrspondence to:}

Michelle M. Kelly, MD, H4/419 CSC,

600 Highland Ave.,

Madison, WI 53792, USA,

Phone: (608) 265-5545,

Fax: (608) 265-8074,

Email: michelle.kelly@wisc.edu
Appl Clin Inform 2017; 8: 265-278

https://doi.org/10.4338/ACI-2016-11-RA-0194

received: November 10, 2016

accepted: January 9, 2017

published: March 15, 2017

Citation: Kelly MM, Dean SM, Carayon P, Wetterneck TB, Hoonakker PLT. Healthcare team perceptions of a portal for parents of hospitalized children before and after implementation. Appl Clin Inform 2017; 8:

265-278

https://doi.org/10.4338/ACI-2016-11-RA-0194

Funding

This work was supported by a Department of Pediatrics' Research and Development Grant at the University of Wisconsin School of Medicine and Public Health. This publication was also supported by the Clinical and Translational Science Award (CTSA) program through the National Center for Advancing Translational Sciences (NCATS), grant UL1TR000427. Dr. Hoonakker's involvement in the study was also partially supported by NSF grant CMMI 1536987. 


\section{Background and Significance}

Patient-centered care, in which the patient is an active participant in managing his or her health, improves healthcare outcomes [1-3] and patient and healthcare team (HCT) satisfaction [4, 5]. To facilitate patient engagement, the Institute of Medicine recommends the implementation of patientcentered health information technologies (IT), such as patient portals [6]. Patient portals are electronic personal health records tethered to electronic health records (EHRs). Portals allow patients and their families to access patient-related healthcare information, facilitate communication with their HCT and, ideally, promote healthcare action [7, 8].

While evidence supporting the use of portals in the ambulatory setting is growing [9-13], recent efforts highlight the potential benefits of using portals to engage hospitalized patients and their families [14-19]. Initial studies suggest that patients and/or families are interested in, willing to use and largely satisfied with portals in the hospital setting [15-19]. While there may be benefits to portal use for patients and their families, portal implementation has been met with considerable resistance from HCT members, in large part due to concerns about portals disrupting their workflow and increasing their workload [20-24]. Theories in health IT implementation research, such as the technology acceptance model, suggest that user perceptions predict the acceptance and use of new technologies [25-30]. Thus, it is important to evaluate HCT perceptions of portals, which influence portal use and any potential benefits their use could provide. Ultimately, the long-term success of portals for hospitalized patients is contingent upon not only use by patients and caregivers and a positive impact on patient health outcomes, but also their acceptance and use by HCTs [31].

\section{Objective}

In a previous study, we described parent perceptions of the use of an EHR-tethered portal application on a tablet computer that provided parents access to real-time information about their child's hospital stay [19]. Overall, parent participants were very satisfied using the portal, reporting that it increased their ability to monitor and understand the care their child needed. In this study, we describe HCT perceptions of challenges with parents using this portal before and 6-months after implementation. We also evaluate HCT perceptions of the impact of portal use on parent questions, parent-HCT communication, HCT workload and work satisfaction, and the quality and safety of care.

\section{Methods}

\subsection{Study design}

In this repeated cross-sectional study, we administered surveys pre- and 6-months post-implementation implementation to assess HCT perceptions of an inpatient portal over time.

\subsection{Setting and participants}

This study was conducted with HCT members on a 24-bed general medical/surgical unit within an 81-bed quaternary care children's hospital in south-central Wisconsin. On this unit, children $<18$ years old are admitted to one of many services, including: hospitalist, cardiology, pulmonology, gastroenterology, neurology, surgery, trauma, orthopedics, transplant and rehabilitation. An EHR (Epic Systems) was implemented in this hospital in 2008. An outpatient patient portal (MyChart, Epic Systems) was implemented in 2009 and an inpatient patient portal (MyChart Bedside, Epic Systems, described in 3.3) in December 2014.

From December 2014-June 2015, a convenience sample of 296 English-speaking parents of children $<12$ years old admitted to the unit were given access to the portal on a hospital-issued tablet computer. Given legal differences in the access of adolescent health information, parents of children 
12 years of age and older were not included. Unit secretaries gave available parents the tablet to use throughout their child's hospitalization. Nurses collected tablets upon discharge.

A multidisciplinary implementation team of stakeholders, including: parents, nurses, resident and attending physicians, unit coordinators, administrators, information services (IS) representatives, health services researchers, and human factors engineers, was created. This team identified all HCT members who interacted with parents of children on the unit and, hence, would be potentially impacted by portal implementation. These eligible participants for the present study included: nurses, pediatric intern and resident physicians, pediatric medical and surgical attending physicians, nurse practitioners, and ancillary staff. Available HCT members participated in a portal training session the month before portal implementation during scheduled, routine departmental meetings.

\subsection{The inpatient portal and implementation process}

MyChart Bedside ( $>$ Figure 1) is a patient portal application tethered to the inpatient EHR delivered on a tablet computer. This application allows patients and/or their families to access information specific to their hospital stay, such as vital signs, their medication list and administration times, lab results, daily schedule, photos of their HCT and a way to send messages/requests. Vital signs, medications and problems lists are released through the portal in real-time. Lab results are released every 90 minutes from 7:00am to 4:30pm. Pathology, culture and radiology results are not released to the portal. Tablets are intended for use only within the hospital and do not include access to the Internet or other applications.

Over one year, the implementation team met biweekly to plan portal implementation. This team made decisions regarding: tablet storage, security and provisioning, portal functionalities offered, lab release, institution-specific education and customizations ( $>$ Figure 1), HCT response times and role expectations, and training material development. The unit coordinator is responsible for provisioning the tablet to the parent as part of the admission process. The nurse is expected to explain the purpose of the portal to the parent, review its functionalities and answer parent questions on the day of admission. All parent portal requests and messages are directed to an EHR work list viewed by the unit coordinator. Depending on content, the unit coordinator is expected to either respond directly or through the portal to the parent and/or ask for assistance from the patient's nurse or physician.

HCT training consisted of a uniform 15-minute didactic overview of how to issue a tablet, a description of portal functionalities, roles of HCT members, hospital expectations for response times (15-30 minutes for requests and 60 minutes for messages) and who to call with technical issues. This was followed by 15-25 minutes of hands-on training, in which HCT members practiced using the portal according to their role and asked questions. After portal training, the IS team was on-site during the first two weeks of portal go-live and made modifications simplifying the provisioning process based on feedback from the HCT. For a more detailed description of the portal and implementation process, see https://www.hipxchange.org/InpatientPortal.

\subsection{Data collection procedure}

From November-December 2014, pre-implementation surveys were administered at the end of portal training to all HCT members present during regularly scheduled department meetings. From June-July 2015, surveys were administered to these HCT members during department meetings. Survey responses were anonymous and not linked to pre-implementation surveys. Reports filed and help desk calls about portal technical issues were tracked. Parent portal requests and messages were collected with tablet metadata. This quality improvement work was deemed exempt from full review by Institutional Review Board at the University of Wisconsin-Madison.

\subsection{Survey}

We constructed pre- and post-implementation paper surveys using items from published literature [32-34]. These items were adapted after piloting and review by the implementation team. On both surveys, we assessed: (1) HCT characteristics (job role, age, education), (2) HCT portal acceptance (1-Dislike very much, don't want to use to 10-Like very much, eager to use), and (3) portal chal- 
lenges. The questions on challenges were adapted from previous literature [34] and consisted of predetermined items and an "other" free text option. When multiple responses to the free-text item were recorded, all were analyzed.

The pre-implementation survey included an item assessing HCT satisfaction with the information received during the portal training. The survey also included items assessing HCT portal perceptions, including: satisfaction and impact of use on parent-HCT communication, HCT workload and work satisfaction, and care quality (response options on a 5-point Likert scale, 1-strongly disagree, 3-neither agree nor disagree and 5-strongly agree). The post-implementation survey included the same HCT perception questions, but only HCT members who reported interacting with at least some parent portal-users were instructed to respond. Post-implementation surveys also included items addressing specific challenges reported by pre-implementation respondents, including: (1) "Did you spend significantly more time responding to parent questions, concerns or requests," (2) "Did parents ask you questions or express concerns about lab results they found on [the portal] before you had seen the results," (3) "Approximately how many parents who had [the portal] contacted you with questions about technical issues related to [the portal]," and (4) Did [the portal] replace other communications with parents, such as face-to-face communication?" We included an item specifically created for this study to assess the reporting of errors by parents: "Did parents notify you of errors in their child's medication list that they found on [the portal]?" The survey also included two open-ended questions: "What was the best thing about [the portal]" and "What was the most difficult thing about [the portal]?” Surveys can be found at: https://www.hipxchange.org/Inpatient Portal.

\subsection{Data Analysis}

Survey data were transcribed into Excel, verified and downloaded into SPSS (Version 20). We excluded missing data and analysed only available data for each variable given the extent of these missing data was $<1 \%$. In all 5-point Likert response questions, responses were combined into three categories: (1) disagree (strongly disagree and disagree), (2) neither agree nor disagree, and (3) agree (strongly agree and agree). "Other" challenges were quantified by aggregating the number of responses into themes identified independently by two researchers and then reconciled. To assess for differences between groups, we used the chi-square test for nominal data and the non-parametric Mann-Whitney and Kruskall Wallis tests for ordinal data.

\section{Results}

\subsection{Healthcare team characteristics}

Pre-implementation, 94 of 100 HCT members who were present and received a survey during departmental meetings completed the survey (response rate 94\%). Post-implementation, 70 of $80 \mathrm{HCT}$ members who were present, received a survey and worked on the unit during the prior 6-months completed the survey (response rate 88\%). Respondents were generally 25-44 years old, received at least a 4-year college degree and had a variety of roles on the unit. There were no significant differences between respondent characteristics pre and post-implementation ( $>$ Table 1 , all $\mathrm{P}>0.05$ ).

\subsection{Healthcare team perceptions}

Pre-implementation, HCT respondents were generally satisfied with the information they received during training sessions. Respondents found the information sufficient (mean=2.35 [SD 1.50]; 1-sufficient, 9-insufficient), timely (mean=2.30 [SD=1.78]; 1-timely, 9-not timely), and useful $($ mean $=2.22$ [SD=1.62]; 1-useful, 9-useless). As shown in $>$ Table 2, many respondents agreed that portal use would improve parent communication with their child's nurse and/or doctor (62\% and $44 \%$, respectively) and improve care quality (53\%). Respondents were less optimistic about the impact of portal use on their work. In all, $71 \%$ reported they would be too busy to incorporate it into their workflow and $52 \%$ anticipated it would increase their workload. 
All HCT respondents anticipated challenges using the portal ( Table 3). Most were concerned that parents would have too many questions about the portal and know test results before their child's doctor or nurse. Of the 22 "other" challenges written in by respondents, 9 described the potential harmful effects of releasing information through the portal (e.g., "parental misinterpretation of clinical stats that we spend years trying to master ... could add undue stress/tension"). The rest described concerns about communication (e.g., "take away from face-to-face patient/parent education") or delayed response times. There were no significant differences in perceived challenges pre-implementation between nurses, attending physicians, intern and/or resident physicians and others, with the exception of: the tablets will get lost or damaged (69\% of nurses, $27 \%$ of attending physicians, $21 \%$ of resident physicians and $50 \%$ of other respondents responded affirmative, $\left.\chi^{2}=15.87, \mathrm{df}=3, \mathrm{p}<0.01\right)$.

Over the following 6 months, 329 of our convenience sample of parents were offered the portal application on a tablet computer and 296 accepted and logged in to it (90\%) [19]. As described in more detail in our previous study of parent perceptions of the portal [19], the portal homepage was accessed an average of 16.5 times per parent user and a majority of parents accessed all portal functionalities (i.e., My health, To learn). Through the portal, 85 parents (29.8\%) made 176 requests (1 to 13 requests per parent who requested). Requests were most commonly for personal care items, a volunteer, water, movie list and linen change. Only 16 parents (5.6\%) sent a total of 36 messages to their child's HCT (1 to 14 among parents who messaged). These included questions regarding treatments, condition updates, requests, and thank you messages to the HCT. Nurses or unit coordinators sent 21 messages in return. These messages included primarily short acknowledgements of parent messages ("You're welcome," "Sure") along with updates on results ("I saw the X-ray was done, I paged the doctor to tell them to read [it] and call me with the results. I will update in person when I know information"), patient encouragement ([Patient], you have been doing so awesome! Keep working hard. We love seeing that smile!"), and documentation that parent questions were answered ("Discussed with mom and dad at the bedside"). There were 10 help desk calls and 17 reports filed for technical support for the portal.

Six months post-portal implementation, HCT acceptance of the portal remained high (mean=7.04 $[\mathrm{SD}=2.33]$ pre vs. mean $=6.75[\mathrm{SD}=1.95]$ post, 1-Dislike very much, don't want to use, 10-Like very much, eager to use at our hospital). Out of all 70 HCT respondents, 34 (49\%) could not estimate the proportion of parents who had the portal because no or very few parents ever mentioned it. Of the 36 respondents (51\%) who reported interacting with at least some parent portal users, most were nurses or ancillary staff (20 nurses, 10 ancillary staff, 4 attending and 2 intern physicians). Compared to pre-implementation respondents, a lower proportion of post-implementation respondents agreed that portal use improved communication between parents and their child's nurse and/or doctor (both $\mathrm{P}<0.001$ ). Similarly, a smaller proportion agreed that the portal increased their workload after implementation $(52 \%$ pre vs. $17 \%$ post, $\mathrm{P}<0.001)$. There were no statistically significant differences between groups (nurses, attending physicians, intern/resident physicians, and other) with regard to workload pre- and post-implementation.

In all post-implementation respondents, $2(3 \%)$ perceived spending more time responding to parent questions, concerns or requests and 20 (29\%) were contacted by parents with portal technical issues. HCT respondents reported that communication with parents using the portal did not replace face-to-face communication (94\%). Thirteen respondents (19\%) reported parents asking lab result questions before the team had seen them; however, only $1(1.4 \%)$ indicated that this was a challenge to portal use. Five percent of HCT respondents were notified by one or more parents of errors in their child's medication list found using the portal.

Compared to pre-implementation, there were significantly fewer challenges reported by respondents 6 months after implementation ( Table 3). Out of 18 "other" challenges reported, 12 were related to unfamiliarity with parents using the portal ("I have not knowingly cared for patients with [the portal]"). The rest included concerns with inaccurate information ("parents saw anticipated discharge dates that were inaccurate") and response time delay. None of the attending physicians reported a challenge post-implementation; however, $85 \%$ of nurses and $52 \%$ of intern and/or resident physicians reported at least 1 challenge $\left(\chi^{2}=19.34, \mathrm{df}=3, \mathrm{p}<0.001\right)$. More nurses $(50 \%)$ than attending physicians and/or residents $(0 \%)$ thought that staff were be skeptical of the portal $\left(\chi^{2}=19.34\right.$, $\mathrm{df}=3, \mathrm{P}<0.001)$. 
The most common responses to the question, "What was the best thing about [the portal]?" were about the benefits of increased parent satisfaction, access to information, recognition of the HCT and engagement in care ("[the portal] helped parents feel more in control and involved with their child's care since they had their health info accessible"). Some respondents also liked that the portal did not affect their daily work. When asked about the most difficult aspects of the portal, some indicated they had difficulty setting the tablet up ("finding time/someone to explain it"). Others suggested "more practice [on issuing the tablet]" or to "have a simple automated walk through of tablet for families".

\section{Discussion}

The implementation of a patient portal intended to engage parents in the care of their hospitalized child had far less perceived impact on the work of the HCT than expected. Although HCT respondents were generally positive about the potential benefits for parents prior to portal implementation, they all anticipated negative implications on their work, such as parents having too many questions, lab results being released too quickly, tablets getting stolen or having technical problems. After 6-months and almost 300 parents using the portal, these concerns did not materialize. In fact, although parents used and were satisfied with the portal [19], almost half of HCT respondents did not report interacting with parents using it and some did not even realize the portal had been implemented. Respondents did not perceive spending more time answering parent questions or that portal use increased their workload.

Results of our study show that HCT members over-estimated the potential negative effects of portal implementation on their workload. While this is one of the first studies using a portal in a pediatric hospital, these findings are consistent with another study that evaluated HCT perceptions of adult patients using an inpatient portal [18]. In this study, HCT participants were generally optimistic about the potential benefits of inpatient portal use for patients (e.g., increased understanding, empowerment); however, a majority perceived that the portal would increase their workload, cause patients to ask too many questions and/or worry. After implementation, HCT participants were less negative about the implications of inpatient portal use on their workload and patient concerns. Another study evaluated an intervention that was similarly intended to engage patients in care by providing patients with access to their physician's clinic notes through an outpatient portal [35]. In this study, physicians also overestimated the burdens of providing patients with information and, afterward, many did not even realize their patients were accessing the notes implementation.

Our results suggest that parents may use the portal as a tool to receive information passively and less as a way to actively communicate through secure-messaging with their inpatient HCT. Both parents and HCT members reported less of an impact of portal use on parent-HCT communication after implementation [19]. Moreover, although parents used the portal, logging in an average of 16.5 times per hospital stay, only 6\% sent a message to their HCT [19]. These results are in contrast to many studies evaluating ambulatory portal use, which suggests secure-messaging rates are higher and may have a larger impact on HCT workload $[36,37]$. Our result could be due to multiple factors. Unlike in the ambulatory setting, the HCT is present for face-to-face communication in the hospital where HCT members are routinely at the bedside or nearby at the nursing station. Parents may feel less comfortable communicating via secure-messaging about more acute problems in the hospital as compared to problems in the ambulatory setting. They also may feel less inclined to message inpatient care team members with whom they are less familiar. Finally, the portal and its messaging functionality may not be optimally integrated into the workflow of parents and/or the HCT. This could be due to limitations in the design of the technology or the implementation process. More evaluation is needed to understand if and/or how secure-messaging could play a role in the inpatient setting. Future research could also evaluate whether sharing information through the portal improves parent-HCT communication in other ways, such as during family-centered rounds.

While the implementation of an inpatient portal on this unit did not appear to have a largely negative repercussions on HCT workload, portal use likely impacted some HCT members more than others. More nurses and ancillary staff reported interacting with parent portal users than physicians. This was expected as it was the role of bedside nurses and unit coordinators to provision the 
tablets and respond to parent requests and messages. Although these HCT respondents reported that parents asked technical questions, they did not report spending significantly more time answering questions from parents who used the portal, such as questions related to early lab result release. These results are consistent with the perceptions of parent survey respondents who used the portal on this unit [19]. About $50 \%$ of parent respondents reported the portal provided them with information they needed, and therefore reduced the number of questions they had for their doctor or nurse, while only $6 \%$ responded that the portal increased their amount of questions. HCT respondents did, however, report the need for more practice using and provisioning the portal and more time to explain the portal to parents on admission. This feedback will be important to consider for further implementation and dissemination efforts where training could be modified to better support HCT members based on their role.

Our results suggest that parents may have found medication errors using the portal and reported these to the HCT. This is supported in other studies $[18,19]$. In one study of adult inpatients using a patient portal, $6 \%$ of portal users and $60 \%$ of HCT members indicated that the portal would help patients find medication errors; however, to our knowledge, error detection was not measured [18]. These results suggest that portals may provide a mechanism for parents to review medications and identify and report potential errors during their child's hospitalization. In the ambulatory setting, medication reconciliation modules that allow patient access to medication information and the ability to identify and even report potential errors within portals have been suggested as a way to prevent harm $[7,8,38]$. Further investigation is needed to identify the proportion of parents who reported errors, characterize these perceived errors and understand actions taken, if any, by HCT members. Moreover, research is needed to design tools that may support recovery or even prevention of errors by patients and/or their proxies.

This study has several limitations. It was conducted with available HCT members working on a general medical/surgical unit within a single, quaternary care children's hospital, which may limit its generalizability. Because survey responses were anonymous, we do not have longitudinal data at the individual level. There were, however, no significant differences between pre- and post-implementation respondent characteristics. Survey completion was voluntary, which may have led to selection bias. However, response rates were high and similar pre- and post-implementation. The portal interface was developed by an EHR provider (Epic Systems) and intentionally implemented with few organizational modifications ( $\$$ Figure 1 ) to minimize institutional development costs. This limited the implementation team's ability to make substantial changes to the technology interface during the implementation process, which may or may not have influenced use and/or HCT perspectives. Acceptance and use of the portal are also heavily influenced by multidisciplinary engagement of stakeholders during the implementation process, a factor that may have also influenced our results and could limit generalizability. Tablets were also only given to a convenience sample of English-speaking parents of children $<12$ years old, limiting the number and type of each HCT member's patients issued the portal. However, every nurse surveyed reported interacting with a parent portal user, which may suggest that some roles on the unit were generally more exposed to the portal than others (e.g., nurses interacted with portal users more than physicians).

\section{Conclusions}

Patient portals are promising tools to engage parents of hospitalized children and may play a role in improving the safety and quality of inpatient care. Although HCT members may be apprehensive of a potential negative impact on their work, these concerns were minimal 6-months after portal implementation at our institution. These data suggest that inpatient portals may be feasibly used and accepted by HCT members. Further investigation is needed to understand the impact of portal use on health outcomes and the safety of inpatient care. 


\section{Question}

After 6-months of parents using a portal application on a tablet computer to access information about their child's hospitalization, most healthcare team respondents reported:

A spending more time answering parent questions

B portal use increased their workload

C fewer challenges than anticipated before portal implementation

D calling the help desk for technical problems and/or stolen tablets

The answer is C. There were significantly fewer challenges reported post-portal implementation. Only $17 \%$ agreed that their workload had increased and 3\% reported spending more time answering parent questions. There were minimal calls to the helpdesk and no stolen tablets.

\section{Clinical Relevance Statement}

Patient portals are promising tools to engage parents of hospitalized children and may play a role in improving the safety and quality of inpatient care. Although HCT members may be apprehensive of a potential negative impact of portal use on their work, these concerns were minimized 6-months after portal implementation at our institution. These data suggest inpatient portals portals will be accepted by HCT members over time.

\section{Contributorship statement}

Michelle M. Kelly, MD conceived and designed the study, obtained funding, participated in data analysis and interpretation, drafted and revised the manuscript, and approved the final version for submission. Shannon Dean, MD assisted with study conception and design, data interpretation, made critical manuscript revisions, and approved the final version for submission. Pascale Carayon, $\mathrm{PhD}$ assisted with study design, data interpretation, made critical manuscript revisions, and approved the final version for submission. Tosha Wetterneck, MD, MS assisted with study design, data interpretation, made critical manuscript revisions, and approved the final version for submission. Peter Hoonakker, PhD assisted with study design, oversaw all data analyses, made critical manuscript revisions, and approved the final version for submission. All authors take responsibility for the integrity of the data and accuracy of data analysis.

\section{Conflicts of Interest}

The authors have no conflicts of interest to declare.

\section{Protection of Human Subjects}

The study was performed in compliance with the World Medical Association Declaration of Helsinki on Ethical Principles for Medical Research Involving Human Subjects, and, as quality improvement, was deemed exempt from full review by the University of Wisconsin Institutional Review Board.

\section{Acknowledgements}

We would like to thank parent portal users and their HCT for their valuable insight and the portal implementation and steering committees for their feedback and support. We would also like to thank Heather Jennings for assistance with data transcription. 
Table 1 Healthcare team (HCT) respondent characteristics pre- and 6 months post-portal implementation*

\begin{tabular}{|c|c|c|}
\hline $\begin{array}{l}\text { HCT respondent } \\
\text { characteristics }\end{array}$ & $\begin{array}{l}\text { Pre, } \mathrm{N}=94 \\
\mathrm{n}(\% \text { of respondents) }\end{array}$ & $\begin{array}{l}\text { Post, } \mathrm{N}=70 \\
\mathrm{n}(\% \text { of respondents) }\end{array}$ \\
\hline \multicolumn{3}{|l|}{ Role* } \\
\hline Nurse & $26(28.0 \%)$ & $20(28.6 \%)$ \\
\hline Nurse Practitioner & $3(3.2 \%)$ & $2(2.9 \%)$ \\
\hline Attending physician & $11(11.8 \%)$ & $10(14.3 \%)$ \\
\hline Intern physician (PGY1) & $13(14.0 \%)$ & $9(12.9 \%)$ \\
\hline Resident physician (PGY2) & $13(14.0 \%)$ & $9(12.9 \%)$ \\
\hline Resident physician (PGY3) & $8(8.6 \%)$ & $5(7.1 \%)$ \\
\hline Other** & $19(20.4 \%)$ & $15(21.4 \%)$ \\
\hline \multicolumn{3}{|l|}{ Age, $y^{*}$} \\
\hline $18-24$ & $6(6.5 \%)$ & $4(5.8 \%)$ \\
\hline $25-34$ & $61(66.3 \%)$ & $42(60.9 \%)$ \\
\hline $35-44$ & $13(14.1 \%)$ & $15(21.7 \%)$ \\
\hline $45-54$ & $8(8.7 \%)$ & $7(10.1 \%)$ \\
\hline 55 or older & $4(4.3 \%)$ & $1(1.4 \%)$ \\
\hline \multicolumn{3}{|l|}{ Education* } \\
\hline Some college or 2-year degree & $4(4.4 \%)$ & $4(5.8 \%)$ \\
\hline 4-year college graduate & $26(28.9 \%)$ & $20(29.0 \%)$ \\
\hline More than 4-year college degree & $60(66.7 \%)$ & $45(65.2 \%)$ \\
\hline
\end{tabular}

*Differences between roles $\left(x^{2}=0.41, d f=6, p=0.99\right)$, age $\left(x^{2}=2.68, d f=4, p=0.61\right)$ and education $\left(x^{2}=0.15, d f=2\right.$, $\mathrm{p}=0.93$ ) of respondents in the pre- and post-surveys were not statistically significant.

** For example: Unit secretary, social worker, case manager, physical therapist 
Table 2 Healthcare team (HCT) perceptions of the portal pre- $(n=94)$ and 6-months post-implementation $\left(n=36^{*}\right)$

\begin{tabular}{|c|c|c|c|c|}
\hline Survey Statement & & Disagree & Neither & Agree \\
\hline \multirow{2}{*}{$\begin{array}{l}\text { The portal will improve/improves parent communication with his/ } \\
\text { her child's nurse.* * }\end{array}$} & Pre & $5.3 \%$ & $33.0 \%$ & $61.7 \%$ \\
\hline & Post & $16.7 \%$ & $66.7 \%$ & $16.7 \%$ \\
\hline \multirow{2}{*}{$\begin{array}{l}\text { The portal will improve/improves parent communication with his/ } \\
\text { her child's doctor(s). * * }\end{array}$} & Pre & $8.5 \%$ & $47.9 \%$ & $43.6 \%$ \\
\hline & Post & $22.2 \%$ & $63.9 \%$ & $13.9 \%$ \\
\hline \multirow[t]{2}{*}{ The portal will increase/increases my workload. * * } & Pre & $16.0 \%$ & $31.9 \%$ & $52.1 \%$ \\
\hline & Post & $41.7 \%$ & $41.7 \%$ & $16.7 \%$ \\
\hline \multirow[t]{2}{*}{ The portal will increase/increases my work satisfaction. } & Pre & $26.6 \%$ & $55.3 \%$ & $18.1 \%$ \\
\hline & Post & $13.9 \%$ & $66.7 \%$ & $19.4 \%$ \\
\hline \multirow[t]{2}{*}{ The portal will improve/improves the quality of patient care. } & Pre & $11.7 \%$ & $35.1 \%$ & $53.2 \%$ \\
\hline & Post & $2.8 \%$ & $44.4 \%$ & $52.8 \%$ \\
\hline \multirow[t]{2}{*}{ Overall, I will be/am satisfied with the portal. } & Pre & $14.9 \%$ & $33.0 \%$ & $52.1 \%$ \\
\hline & Post & $5.6 \%$ & $47.2 \%$ & $47.2 \%$ \\
\hline
\end{tabular}

*Post-implementation, only HCT members who reported knowingly interacting with at least some parents using the portal were asked to respond to these questions (36 out of 70 respondents). Results are expressed in percentages of respondents who agreed, neither agreed or disagreed, or disagreed with the survey statements. Note that the questions in the pre-implementation survey were worded in the future tense (e.g. will be satisfied) and in the post-implementation survey in the past or present tense (e.g. am satisfied).

** $P<0.01$

Table 3 Challenges of portal use perceived by healthcare team (HCT) respondents pre- and 6-months post-portal implementation*

\begin{tabular}{|l|l|l|l|}
\hline Challenges perceived by HCT respondents & $\begin{array}{l}\text { Pre, N=94 } \\
\mathbf{n}(\%)\end{array}$ & $\begin{array}{l}\text { Post, N=70 } \\
\mathbf{n}(\%)\end{array}$ & P-value \\
\hline $\begin{array}{l}\text { Parents will have/have too many questions about the information on } \\
\text { the portal }\end{array}$ & $65(69.1 \%)$ & $2(2.9 \%)$ & $\mathrm{P}<0.001$ \\
\hline $\begin{array}{l}\text { Parents will know/know test results before their child's doctor or } \\
\text { nurse }\end{array}$ & $61(64.9 \%)$ & $1(1.4 \%)$ & $\mathrm{P}<0.001$ \\
\hline \begin{tabular}{l} 
Staff will be/are skeptical of the portal \\
\hline The tablets will get/get lost or damaged
\end{tabular} & $40(42.6 \%)$ & $15(21.4 \%)$ & $\mathrm{P}<0.001$ \\
\hline $\begin{array}{l}\text { There will not be/is not enough computer technical support } \\
\text { The information will not be/is not useful for parents }\end{array}$ & $39(41.4 \%)$ & $1(1.4 \%)$ & $\mathrm{P}<0.001$ \\
\hline It will be/is too hard for me to learn to use & $8(27.7 \%)$ & $1(1.4 \%)$ & $\mathrm{P}<0.001$ \\
\hline None & $1(1.1 \%)$ & $5(7.1 \%)$ & $\mathrm{NS}$ \\
\hline Other** & $0(0 \%)$ & $27(38.6 \%)$ & $\mathrm{PS}<0.001$ \\
\hline Total number of challenges mentioned by respondents & $19(20.2 \%)$ & $16(22.9 \%)$ & $\mathrm{NS}$ \\
\hline Average number of challenges per respondent & 259 & 41 & $\mathrm{P}<0.001$ \\
\hline
\end{tabular}

${ }^{*}$ Respondents could choose all that apply; therefore, totals exceed the number of respondents

${ }^{* *}$ Other challenges described in text 


\section{References}

1. Stewart M, Brown JB, Donner A, McWhinney IR, Oates J, Weston WW, Jordan J. The impact of patientcentered care on outcomes. The Journal of Family Practice 2000; 49(9): 796-804.

2. Little P, Everitt H, Williamson I, Warner G, Moore M, Gould C, Ferrier K, Payne S. Observational study of effect of patient centredness and positive approach on outcomes of general practice consultations. BMJ 2001; 323(7318): 908-911.

3. Maeng DD, Graf TR, Davis DE, Tomcavage J, Bloom FJ, Jr. Can a Patient-Centered Medical Home Lead to Better Patient Outcomes? The Quality Implications of Geisinger's ProvenHealth Navigator. American journal of medical quality : the official journal of the American College of Medical Quality 2012; 27(3): 210-216.

4. Wanzer MB, Booth-Butterfield M, Gruber K. Perceptions of health care providers' communication: relationships between patient-centered communication and satisfaction. Health Communication 2004; 16(3): 363-383.

5. Wolf DM, Lehman L, Quinlin R, Zullo T, Hoffman L. Effect of patient-centered care on patient satisfaction and quality of care. Journal of Nursing Care Quality 2008; 23(4): 316-321.

6. Committee on Patient Safety and Health Information Technology. Health IT and Patient Safety: Building Safer Systems for Better Care. Washington (DC): National Academies Press (US); 2011 Nov.

7. Tang PC, Ash JS, Bates DW, Overhage JM, Sands DZ. Personal health records: definitions, benefits, and strategies for overcoming barriers to adoption. Journal of the American Medical Informatics Association: JAMIA 2006; 13(2): 121-126.

8. Schnipper JL, Gandhi TK, Wald JS, Grant RW, Poon EG, Volk LA, Businger A, Siteman E, Buckel L, Middleton B. Design and implementation of a web-based patient portal linked to an electronic health record designed to improve medication safety: the Patient Gateway medications module. Informatics in Primary Care 2008; 16(2): 147-155.

9. Ammenwerth E, Schnell-Inderst P, Hoerbst A. The impact of electronic patient portals on patient care: a systematic review of controlled trials. Journal of Medical Internet Research 2012; 14(6): e162.

10. Goldzweig CL, Orshansky G, Paige NM, Towfigh AA, Haggstrom DA, Miake-Lye I, Beroes JM, Shekelle PG. Electronic patient portals: evidence on health outcomes, satisfaction, efficiency, and attitudes: a systematic review. Ann Intern Med 2013; 159(10): 677-687.

11.Davis Giardina T, Menon S, Parrish DE, Sittig DF, Singh H. Patient access to medical records and healthcare outcomes: a systematic review. Journal of the American Medical Informatics Association: JAMIA 2014; 21(4): 737-741.

12. Kalra D, Fernando B. A review of the empirical evidence of the healthcare benefits of personal health records. Yearbook of Medical Informatics 2013; 8(1): 93-102.

13. Kruse CS, Bolton K, Freriks G. The effect of patient portals on quality outcomes and its implications to meaningful use: a systematic review. Journal of Medical Internet Research 2015; 17(2): e44.

14.Prey JE, Woollen J, Wilcox L, Sackeim AD, Hripcsak G, Bakken S, Restaino S, Feiner S, Vawdrey DK. Patient engagement in the inpatient setting: a systematic review. Journal of the American Medical Informatics Association: JAMIA 2014; 21(4): 742-750.

15. Greysen SR, Khanna RR, Jacolbia R, Lee HM, Auerbach AD. Tablet computers for hospitalized patients: a pilot study to improve inpatient engagement. J Hosp Med 2014; 9(6): 396-399.

16. Vawdrey DK, Wilcox LG, Collins SA, Bakken S, Feiner S, Boyer A, Restaino SW. A tablet computer application for patients to participate in their hospital care. AMIA Annual Symposium Proceedings 2011: 1428-1435.

17. O'Leary KJ, Lohman ME, Culver E, Killarney A, Randy Smith G, Jr., Liebovitz DM. The effect of tablet computers with a mobile patient portal application on hospitalized patients' knowledge and activation. Journal of the American Medical Informatics Association: JAMIA 2016; 23(1): 159-165.

18. Pell JM, Mancuso M, Limon S, Oman K, Lin CT. Patient access to electronic health records during hospitalization. JAMA Internal Medicine 2015; 175(5): 856-858.

19. Kelly MM, Hoonakker PL, Dean SM. Using an inpatient portal to engage families in pediatric hospital care. Journal of the American Medical Informatics Association: JAMIA 2017; 24(1): 153-161.

20. Miller DP, Jr., Latulipe C, Melius KA, Quandt SA, Arcury TA. Primary Care Providers' Views of Patient Portals: Interview Study of Perceived Benefits and Consequences. Journal of Medical Internet Research 2016; 18(1): e8.

21. Keplinger LE, Koopman RJ, Mehr DR, Kruse RL, Wakefield DS, Wakefield BJ, Canfield SM. Patient portal implementation: resident and attending physician attitudes. Fam Med 2013; 45(5): 335-340. 
22. Wakefield DS, Mehr D, Keplinger L, Canfield S, Gopidi R, Wakefield BJ, Koopman RJ, Belden JL, Kruse R, Kochendorfer KM. Issues and questions to consider in implementing secure electronic patient-provider web portal communications systems. International Journal of Medical Informatics 2010; 79(7): 469-477.

23. Kittler AF, Carlson GL, Harris C, Lippincott M, Pizziferri L, Volk LA, Jagannath Y, Wald JS, Bates DW. Primary care physician attitudes towards using a secure web-based portal designed to facilitate electronic communication with patients. Informatics in Primary Care 2004; 12(3): 129-138.

24. Carayon P, Hoonakker PLT, Cartmill R, Hassol A. Using Health Information Technology (IT) in Practice Redesign: Impact of Health IT on Workflow. Patient-Reported Health Information Technology and Workflow. (Prepared by Abt Associates under Contract No. 290-2010-00031I). AHRQ Publication No. 15-0043-EF. Rockville, MD: Agency for Healthcare Research and Quality. May 2015.

25. Carayon P, Hundt AS, Wetterneck TB. Nurses' acceptance of Smart IV pump technology. International Journal of Medical Informatics 2010; 79(6): 401-411.

26. Carayon P, Cartmill R, Blosky MA, Brown R, Hackenberg M, Hoonakker P, Hundt AS, Norfolk E, Wetterneck TB, Walker JM. ICU nurses' acceptance of electronic health records. Journal of the American Medical Informatics Association: JAMIA 2011; 18(6): 812-819.

27. Hoonakker PL, Carayon P, Brown RL, Cartmill RS, Wetterneck TB, Walker JM. Changes in end-user satisfaction with Computerized Provider Order Entry over time among nurses and providers in intensive care units. Journal of the American Medical Informatics Association: JAMIA 2013; 20(2): 252-259.

28. Karsh BT. Beyond usability: designing effective technology implementation systems to promote patient safety. Quality \& Safety in Health Care 2004; 13(5): 388-394.

29. Holden RJ, Karsh BT. The technology acceptance model: its past and its future in health care. Journal of Biomedical Informatics 2010; 43(1): 159-172.

30.Hu PJ, Chau PY. Physician acceptance of telemedicine technology: an empirical investigation. Topics in Health Information Management 1999; 19(4): 20-35.

31. Gagnon MP, Ngangue P, Payne-Gagnon J, Desmartis M. m-Health adoption by healthcare professionals: a systematic review. Journal of the American Medical Informatics Association: JAMIA 2016; 23(1): 212-220.

32. Hoonakker PL, Cartmill RS, Carayon P, Walker JM. Development and Psychometric Qualities of the SEIPS Survey to Evaluate CPOE/EHR Implementation in ICUs. International Journal of Healthcare Information Systems and Informatics 2011; 6(1): 51-69.

33. Cox ED, Carayon P, Hansen KW, Rajamanickam VP, Brown RL, Rathouz PJ, DuBenske LL, Kelly MM, Buel LA. Parent perceptions of children's hospital safety climate. BMJ Quality \& Safety 2013; 22(8): 664-671.

34. Leveille SG, Walker J, Ralston JD, Ross SE, Elmore JG, Delbanco T. Evaluating the impact of patients online access to doctors' visit notes: designing and executing the OpenNotes project. BMC Medical Informatics and Decision Making 2012; 12: 32.

35.Delbanco T, Walker J, Darer JD, Elmore JG, Feldman HJ, Leveille SG, Ralston JD, Ross SE, Vodicka E, Weber VD. Open notes: doctors and patients signing on. Ann Intern Med 2010; 153(2): 121-125.

36. Cronin RM, Davis SE, Shenson JA, Chen Q, Rosenbloom ST, Jackson GP. Growth of Secure Messaging Through a Patient Portal as a Form of Outpatient Interaction across Clinical Specialties. Applied Clinical Informatics 2015; 6(2): 288-304.

37. Shenson JA, Cronin RM, Davis SE, Chen Q, Jackson GP. Rapid growth in surgeons' use of secure messaging in a patient portal. Surgical Endoscopy 2016; 30(4): 1432-1440.

38. Kaushal R, Barker KN, Bates DW. How can information technology improve patient safety and reduce medication errors in children's health care? Archives of Pediatrics \& Adolescent Medicine 2001; 155(9): 1002-1007. 